\title{
PUBLICAR, PUBLICAR, PUBLICAR... ATÉ AONDE VAI A ÉTICA CIENTÍFICA?
}

\author{
Patrícia Honório Silva Santos ${ }^{1}$, Laisla Pires Dutra ${ }^{1}$, Edite Lago da Silva Sena ${ }^{1}$, Sergio Donha Yari ${ }^{1}$, Rita \\ Narrimam Silva de Oliveira Boery ${ }^{1}$
}

Resumo: O objetivo do estudo consistiu em analisar a literatura existente sobre a fraude científica e seus aspectos bioéticos. Revisão de literatura do tipo integrativa, sendo os dados coletados nas bases de dados Lilacs e SciELO, por meio dos descritores, fraude científica e plágio. Foram encontrados 7 artigos que atenderam aos critérios de inclusão. Os resultados foram categorizados em três eixos temáticos. Histórico da fraude científica; Fraude científica e implicaçóes bioéticas; e Medidas adotadas. Concluiu-se que os pesquisadores e acadêmicos devem estar sempre revendo suas posturas éticas diante das publicaçóes científicas. Ainda há lacunas sobre as fraudes científicas, especialmente relacionando-as aos aspectos bioéticos. Assim, esse estudo poderá contribuir para as reflexôes sobre a temática.

Palavras-chave: plágio, publicação, bioética

\section{Publicar, publicar, publicar. ¿¿Dónde va la ética científica?}

Resumen: El objetivo de este estudio fue analizar la literatura existente sobre fraude científico y sus problemas bioéticos. Es un tipo de revisión bibliográfica integrativa y de datos recogidos en las bases Lilacs y SciELO, utilizando como descriptores "fraude científico" y "plagio". Se encontraron 7 artículos que cumplieron con los criterios de inclusión. Los resultados se clasificaron en tres temas: historia del fraude científico; fraude científico e implicaciones bioéticas, y medidas adoptadas. Se llegó a la conclusión de que los investigadores y académicos debían estar siempre revisando sus posturas éticas ante las publicaciones científicas. Todavía hay lagunas sobre el fraude científico, particularmente las relacionadas con cuestiones bioéticas. Este estudio puede contribuir a mayores reflexiones sobre el tema.

Palabras clave: plagio, publicación, bioética

\section{To publish, publish, publish. Where it is scientific ethics?}

\begin{abstract}
The scope of this study was to analyze the existing literature on scientific fraud and their bioethical issues. Type of integrative literature review and the data collected in the Lilacs and SciELO databases, using descriptors, scientific fraud and plagiarism. Found 7 articles that met the inclusion criteria. The results were categorized into three themes, History of scientific fraud; Scientific fraud and bioethical implications; and adopted measures. It was concluded that researchers and academics should always be reviewing their ethical stances in the face of scientific publications. There are still gaps about scientific fraud, particularly relating them to bioethical issues. Thus, this study may contribute to the reflections on the theme.
\end{abstract}

Key words: plagiarism, publishing, bioethics

\footnotetext{
${ }^{1}$ Universidade Estadual do Sudoeste da Bahia (UESB), Jequié (BA), Brasil

Correspondência: patyhonorios@hotmail.com
} 


\section{Introdução}

As fraudes científicas representam motivo de grande preocupação das comunidades cientificas nos últimos anos, implicando em violação moral e legal de direitos autorais e desrespeito com a humanidade. Em vista disso, as discussóes sobre o envolvimento de questóes éticas e bioéticas têm se tornado muito presentes nas produçóes científicas, especialmente, naquelas que envolvem seres humanos(1).

Neste cenário, a preocupação dos pesquisadores em publicar, para atender aos órgãos científicos e agências de fomento à pesquisa a que estão vinculados, temos atormentado. Sufocados pelo lema "publicar ou perecer", são pressionados a publicar em revistas de alto impacto, ou serão deixados para trás no âmbito da academia. Assim, sob essa constante apreensão para publicar e ascender profissionalmente, muitos pesquisadores acabam descuidando e cometendo infraçóes éticas(2).

As infraçóes éticas que denotam a desonestidade científica compreendem desde a fabricação e exclusão dos dados, ao plágio, roubo de prioridade, inclusão ou exclusão, inadequadas de autores, perda de controle no uso de cargos ou de recursos de pesquisa, entre outros(3).

Cabe destacar que o papel da ciência consiste em produzir novos conhecimentos, e que esses conhecimentos sejam devolvidos à população, quer subsidiando a formulação de políticas públicas, pelo descobrimento de novos recursos, técnicas ou métodos terapêuticos, quer entre tantas outras formas de devolver o produto do trabalho dos pesquisadores à comunidade, de modo que as desonestidades científicas refletem em todo o conjunto que abrange as comunidades científicas, até a população em geral, além de constituir ato espúrio perante a legislação do país.

Portanto, as discussóes sobre a fraude científica devem abranger toda a sociedade, visto que suas consequências náo se restringem às academias, mas afeta direta e negativamente nossas vidas diariamente(4).

Esse estudo parte do pressuposto de que, a partir de seus resultados, será possível ampliar as refle- xões sobre os aspectos bioéticos que envolvem as fraudes científicas, as quais, por sua vez, poderão viabilizar mecanismos de controle, almejando uma produção de ciência com qualidade e respeito.

Assim, este artigo tem como questóes norteadoras: o que a literatura apresenta sobre a fraude científica? Até onde vão as questôes éticas nas publicaçóes científicas? Com vistas a responder a esses questionamentos, esta pesquisa objetiva, analisar a literatura existente sobre a fraude científica e seus aspectos bioéticos.

\section{Metodologia}

Trata-se de uma pesquisa descritiva, do tipo revisão integrativa da literatura, que consiste em um método de pesquisa científica que objetiva conhecer e tecer uma análise crítica sobre as evidências de um tema em questão, de modo que seu produto final permite identificar lacunas e fornecer conhecimentos aprofundados sobre o tema investigado(5).

Para a realização dessa revisão integrativa foi realizado um levantamento bibliográfico na Biblioteca Virtual de Saúde (BVS), a partir das bases de dados, Scielo (Scientific Eletronic Library Online) e LILACS (Literatura Latino-Americana e do Caribe em Ciências da Saúde), no período de abril de 2015, através dos descritores "plágio" e "fraude científica”.

Os critérios utilizados para a inclusão dos artigos foram: artigos escritos no idioma português; publicado nos últimos 10 anos; que fossem disponíveis em texto completo; e que atendessem ao objetivo proposto. Foram excluídos, editoriais e diretrizes.

A princípio, pelos descritores e suas combinaçôes, surgiram 5686 estudos. No entanto, após a aplicação dos critérios de inclusão, foram selecionados 7 artigos. Após essa seleção, as seguintes etapas foram seguidas: leitura dos resumos e, posteriormente, leitura do artigo na íntegra, observando se realmente contemplavam ao objetivo do estudo e nova leitura, de forma analítica e crítica, para extrair os resultados e características relevantes. 
Para a análise dos dados e síntese dos artigos foi utilizada uma figura sinóptica, contemplando as seguintes características: Periódico/Ano; Título; Autoria; Procedência; Objetivos; e Resultados. $\mathrm{Na}$ sequência, a discussão foi realizada fundamentada pela integração de outros estudos que tratavam da temática da preservação dos aspectos bioéticos frente às publicaçóes científicas e fornecessem embasamento às categorias emergidas dos resultados do presente estudo.

\section{Resultados}

Esta revisão integrativa foi, assim, composta por 7 artigos que atenderam aos critérios de inclusão estabelecidos. Desses artigos, 5 foram encontrados na base de dados da Scielo e 2 na base de dados da LILACS, sendo apenas um, de origem internacional. Esta e demais características são visualizadas no quadro sinóptico 1 , seguinte.

Para nortear a discussão foram identificados três eixos temáticos, a saber: histórico da fraude científica; Fraude científica e implicações bioéticas; e medidas adotadas. Os artigos que originaram o eixo temático, histórico da fraude científica, foram aqueles que apresentaram os motivos que levam à disseminação da fraude na ciência e seus marcos históricos; o eixo temático, fraude científica e implicaçóes bioéticas foi originado de artigos que apresentaram os diferentes tipos de fraude científica e suas implicações para o pesquisador, ciência e sociedade; já o eixo temático, medidas adotadas, foi criado a partir dos artigos que apontaram estratégias que vêm sendo utilizadas para minimizar, ou, quem sabe, coibir as más condutas na ciência.

\section{Discussáo}

Por meio das análises dos resultados foi possível perceber que nenhum dos artigos abordou diretamente a fraude científica e sua relação com a bioética. No entanto, em todos os artigos analisados constatou-se que a fraude científica é uma prática maléfica e desrespeitosa, contradizendo, portanto, as questóes bioéticas. Foi nesta perspectiva que emergiram 3 eixos temáticos para orientar essa discussão.

\section{Histórico da fraude científica}

A preocupação com questôes éticas envolvidas nas publicações científicas existe há muito tempo, sendo visualizada em âmbito mundial através de discussóes que distintos países promovem, na tentativa de conscientizar pesquisadores e subsidiar a elaboração de dispositivos legais para orientar os comportamentos dos cientistas, de modo que a fraude científica não consiste em um fato novo(4).

Nesse sentido, Hossne e Vieira(13) apontam que a fraude é tão velha quanto a humanidade, sendo apresentado em seu artigo diversos casos de fraude científica, que envolvem plágios, falsificação, duplicação, fabricação e destruição de dados, e datam desde 1996 a 2005. Um dos casos relatados nesse estudo refere-se ao texto que mais chamou atenção na pesquisa envolvendo células-troncos, em que um cientista coreano, que teria sido pioneiro na produção de embrióes humanos clonados, forjou os dados, de modo que, na realidade, embrióes humanos não foram clonados(14).

Dessa forma, apesar do plágio e demais tipos de fraude científica ser um problema de longa data no contexto histórico, o cenário em que eles se inserem na atualidade apresentou mudanças, de maneira que diante as atuais discussóes éticas e de integridade na ciência, condutas fraudulentas são inaceitáveis(4).

Apesar de inaceitáveis, destaca-se, entretanto, que essas condutas fraudulentas são motivadas por questóes relacionadas à personalidade, passando por razóes características da atualidade, como o crescente número de pesquisadores e as competiçóes entre eles, seja por verbas ou reconhecimentos; a pressão pela publicação e a necessidade que um pesquisador tem em ser renomado e alcançar status e poder, podem fazer com que os pesquisadores atropelem os aspectos éticos(13).

Acrescenta-se, ainda, que a maior visibilidade da fraude em pesquisas científicas no contexto atual deve-se também ao maior acesso à Internet e ao desenvolvimento de programas de computador que facilitam tanto a detecçáo de fraudes, quanto a sua efetivaçãoo(15). 


\section{Fraude científica e implicaçóes bioéticas}

A segunda classe temática demonstra que um cientista, ao exercer sua atividade de pesquisa, deve observar deveres oriundos dos valores éticos próprios aos cientistas, passando pelos mais gerais, como o respeito a integridade física, moral e psicológica dos seres humanos e animais. No que se refere aos valores éticos inerentes aos cientistas, o que vem sendo chamado de integridade científica, trata-se daqueles valores conferidos aos cientistas, devido ao seu compromisso com a construção da ciência como bem coletivo, de modo que o pesquisador deve privar-se de agir de maneira intencional ou negligente, impedindo ou prejudicando esse trabalho coletivo de construção da ciência e apropriaçáo coletiva de seus resulta$\operatorname{dos}(16)$.

No entanto, o que se tem observado é que alguns cientistas estáo produzindo ciência sem observar tais valores, comprometendo a qualidade e integridade da pesquisa. Nesse sentido, observa-se que o número de publicaçóes tem crescido, no entanto, paralelo a essa crescente ascensão científica, a ciência perde seu sentido, na medida em que produz conhecimentos que são questionáveis, visto que os valores éticos, morais e a honestidade, têm ficado latentes.

Existem diferentes tipos de más condutas na ciência, os quais compreendem a fabricação e falsificação de dados, o plágio, o auto plágio, a ocultação de conflitos de interesses, o armazenamento inadequado dos registros da pesquisa, a retenção de informaçóes e a omissão de dados(16).

A fabricação de dados refere-se à invenção de itens da pesquisa e a falsificação por sua vez, trata-se da modificação dos dados, ou sua omissão, para que o pesquisador consiga garantir sua hipótese, de modo que a pesquisa não seja representada com precisão(17).

O plágio, entretanto, consiste em um tipo de fraude científica muito frequente, sendo conceituado como a utilização de ideias de outros autores sem as devidas referências, fazendo com que opiniōes se apresentem sob nova autoria. Ressalta-se que se configuram como plágio, mesmo se essas idéias estejam em outros idiomas(18). O autoplágio, por sua vez, compreende a republicação de resultados como se fossem inéditos, sem fazer menção à publicação anterior (19).

Destaca-se que o plágio representa violação tanto moral, quanto legal, de direitos autorais e propriedade intelectual(20), acarretando danos ao autor que cometeu o plágio, devido os prejuízos morais, profissionais e financeiros e ao verdadeiro autor do texto plagiado que vê sua opiniáo ser apropriada por outrem $(21)$.

No que se refere aos conflitos de interesses, muito comuns nas pesquisas médico-farmacológicas, em que é necessário que as indústrias farmacêuticas formem parcerias com instituiçóes e médicos pesquisadores, através do financiamento da pesquisa, para que o teste clínico seja realizado, salienta-se que estes têm caráter voluntário. Não existe um controle sobre o mesmo, o que pode comprometer a qualidade da pesquisa científica, alterando resultados e trazer repercussóes negativas à saúde dos participantes e demais seres humanos, devido aos efeitos adversos que podem ocasionar(10).

Embora muitas vezes seja considerado apenas como um mau comportamento e desvio leve, os problemas relacionados com a autoria em trabalhos científicos são bastante comuns, observando-se inclusão de nome de pessoa em trabalho dos quais essa não participou, por exemplo, quando um professor, ou líder de algum grupo exige que seu nome seja incluso em trabalhos realizados pelos pertencentes ao grupo ou quando é incluso o nome de uma pessoa reconhecida na área da pesquisa, para aumentar as chances de publicação e exclusão de nomes de indivíduos que realmente tenha participado do trabalho, em casos, por exemplo, de desentendimentos e disputas entre pesquisadores (7).

A ciencia deve avançar, porém esse avanço deve ser realizado, obedecendo preceitos éticos e respeitando a dignidade humana(1). A desonestidade científica gera resultados científicos inúteis, de modo que todos os esforços, investimentos, são jogados fora, além de representar um sério risco à humanidade devido aos danos que podem causar. 


\section{Medidas adotadas}

O terceiro eixo temático diz respeito à conduta diante da fraude científica. Azevedo(22) salienta que os desafios éticos na ciência nasceram no século XX e perduram até os dias atuais, clamando por posturas éticas, tanto na produção de conhecimentos, quanto nas aplicaçóes de seus resultados.

Russo(4), ao considerar a preocupação com a integridade e as questóes éticas na ciência, admite que esta surgiu nos anos 80, nos Estados Unidos, através dos relatos de fraudes científicas realizadas em instituições de prestígio, por pesquisadores renomeados. Fatos que logo foram disseminados na mídia e ganharam repercussão, náo apenas em âmbitos institucionais, mas na sociedade como um todo, fazendo com que as universidades americanas e, posteriormente, as européias, elaborassem códigos de condutas, aspirando à ética e à integridade na pesquisa. Assim, foi criado nos EUA, no ano de 1992, o Office Research Integrity (ORI)(4), e em 1997 o Committe on Publication Ethics (COPE)(18).

No Brasil, o conceito de preservação da integridade humana no campo da pesquisa nasceu com a criação da resolução no 196 de 1996, do Conselho Nacional de Saúde, que instituiu o sistema CEP/CONEP, ampliando as questôes sobre ética na pesquisa(22). No entanto, esse sistema náo se responsabilizou pela fiscalização da integridade na pesquisa, de modo que essa função fica a cargo das instituiçôes e comunidades científicas, visto que o país não conta com um órgão específico para identificar a desonestidade na ciência e adotar medidas punitivas(23).

Cabe ressaltar que os episódios de fraude divulgados pela imprensa fizeram com que esse problema passasse a ser de interesse da sociedade e das agências de fomento e governos, sendo exigidos, portanto, uma maior vigilância sobre a problemática e criados mecanismo para conter, aplicar sançóes e acompanhar os casos de fraudes científicas(4).

Por conseguinte, em maio de 2011, foi criada uma comissão no Conselho Nacional de Desenvolvimento Científico e Tecnológico - CNPq, formada por cientistas experientes, com o objeti- vo de propor diretrizes para a ética e integridade na ciência(24) e em setembro do mesmo ano, publicado pela Fundaçáo de Amparo à Pesquisa no Estado de São Paulo (FAPESP), o Código de Boas Práticas Científicas, também, com a finalidade de implantar uma cultura de integridade ética da pesquisa(25).

Além desses dispositivos legais, vêm sendo discutidos critérios de autoria, visto que muitos pesquisadores se juntam pra alcançar elevados índices de produção, cometendo, muitas vezes, maus comportamentos em relaçáo à autoria(7) e também programas anti-plágios tem sido desenvolvidos e aderidos por diversas instituiçóes e editores de revistas, para facilitar a detecçáo e combate às fraudes(12).

Ressalta-se, entretanto, que a desonestidade científica deve ser tomada como um desafio para instituição, pesquisadores, professores e sociedade, pois o envolvimento de todos é fundamental na adoção de uma postura ética pelos futuros pesquisadores, seja através da transmissão de bons exemplos, ou através de ementas que contemplem o conteúdo nos cursos, ou ainda através de sançôes adotadas pelas instituiçóes, na tentativa de coibir os comportamentos inadequados, visto que se estas posturas éticas forem introduzidas no âmbito das instituiçóes de ensino superior e entre profissionais de saúde, nossa ciência apresentará maior veracidade e, portanto, mais qualidade(8).

\section{Consideraçóes finais}

Os pesquisadores e acadêmicos devem estar sempre revendo suas posturas éticas diante das publicaçôes científicas, pois motivados pela vasta ascensão da ciência, ampliação dos programas de pós-graduação, a precisão de títulos e formas de avalição da produção, que passou a ser quantitativa em detrimento da qualitativa, passaram a produzir conhecimentos científicos inadequados e inaceitáveis, pois infligem aspectos éticos e morais.

Os resultados desse estudo evidenciaram que existem ainda lacunas sobre as fraudes científicas, especialmente, relacionando-as aos aspectos bioéticos no cenário brasileiro, sendo constatado que, apesar do reconhecimento e grande preocupação 
com o tema, o país não conta com um órgão regulatório, capaz de exercer o controle sobre a ética na ciência.

Constatou-se, também, a importância da participação articulada entre instituições, agências de fomento, pesquisadores e sociedade para coibir as más condutas na ciência e, portanto, fazer os conhecimentos progredirem dentro de padróes éticos.

Logo, verificou-se que o objetivo proposto nesse estudo foi alcançado, sendo realizada a análise da literatura existente sobre a fraude científica, relacionando-a às questôes bioéticas e, possibilitando, ampliar as reflexóes sobre a temática, com vista a adoção de comportamentos mais fidedignos e éticos nas publicações científicas. 
Acta Bioethica 2017; 23 (1): 63-70

\begin{tabular}{|c|c|c|c|c|c|}
\hline $\begin{array}{l}\text { Periódico/ } \\
\text { Ano }\end{array}$ & Título & Autoria & $\begin{array}{l}\text { Proce- } \\
\text { dência }\end{array}$ & Objetivo & Resultados \\
\hline $\begin{array}{l}\text { RevAssocMed Bras., } \\
2007 .\end{array}$ & $\begin{array}{l}\text { Escrtitores- } \\
\text { fantasmas e } \\
\text { o comércio } \\
\text { de trabalhos } \\
\text { científicos na } \\
\text { internet: a ciência } \\
\text { em risco }\end{array}$ & $\begin{array}{l}\text { Grieger MCA. } \\
\text { (6) }\end{array}$ & Scielo & $\begin{array}{l}\text { Analisar o comércio } \\
\text { de trabalhos } \\
\text { científicos na } \\
\text { internet e o modo } \\
\text { como são oferecidos } \\
\text { esses serviços }\end{array}$ & $\begin{array}{l}\text { Dez empresas } \\
\text { aceitaram as condições } \\
\text { impostas, incluindo } \\
\text { a aprovação prévia por } \\
\text { um comitê de ética em } \\
\text { pesquisa e a utilização } \\
\text { das normas de } \\
\text { Vancouver. Apenas uma } \\
\text { se negou por se recusar } \\
\text { a fazer pesquisa de } \\
\text { campo }\end{array}$ \\
\hline $\begin{array}{l}\text { RevBrasCirCardiovasc., } \\
2010 .\end{array}$ & $\begin{array}{l}\text { Autoria em artigos } \\
\text { científicos: os } \\
\text { novos desafios }\end{array}$ & $\begin{array}{l}\text { Garcia CC. et } \\
\text { al.(7) }\end{array}$ & Scielo & $\begin{array}{l}\text { Apresentar critérios } \\
\text { de autoria e razões } \\
\text { para o crescimento } \\
\text { de coautoria }\end{array}$ & $\begin{array}{l}\text { Faz-se necessário } \\
\text { discutir os critérios } \\
\text { de autoria para sanar } \\
\text { dúvidas e assegurar os } \\
\text { direitos do autor. }\end{array}$ \\
\hline Rev. Bioét., 2010. & $\begin{array}{l}\text { O tema da } \\
\text { integridade } \\
\text { científica nas pós- } \\
\text { graduações } \\
\text { em saúde no Brasil }\end{array}$ & Santana CC.(8) & LILACS & $\begin{array}{l}\text { Conhecer a } \\
\text { preocupação dos } \\
\text { programas de } \\
\text { pós-graduação } \\
\text { em saúde na } \\
\text { formação de novos } \\
\text { pesquisadores, } \\
\text { incluindo } \\
\text { ensinamentos sobre } \\
\text { integridade científica }\end{array}$ & $\begin{array}{l}\text { Não existe preocupação } \\
\text { com o tema da } \\
\text { integridade científica } \\
\text { por parte da maioria } \\
\text { dos programas de pós- } \\
\text { graduação em saúde } \\
\text { no país. }\end{array}$ \\
\hline Psicologia USP, 2011. & $\begin{array}{l}\text { Equívocos na } \\
\text { publicação } \\
\text { científica: algumas } \\
\text { considerações }\end{array}$ & Guedes MC.(9) & Scielo & $\begin{array}{l}\text { Discutir aspectos } \\
\text { técnicos e éticos do } \\
\text { trabalho de autor de } \\
\text { artigo científico e de } \\
\text { editor de periódico } \\
\text { científico }\end{array}$ & $\begin{array}{l}\text { Deve-se abordar a } \\
\text { pressão por produção } \\
\text { quantificável. }\end{array}$ \\
\hline Rev. bioét. (Impr.). 2013. & $\begin{array}{l}\text { Conflito de } \\
\text { interesses na } \\
\text { pesquisa médico- } \\
\text { farmacológica }\end{array}$ & $\begin{array}{l}\text { Souza RP. et } \\
\text { al.(10) }\end{array}$ & Scielo & $\begin{array}{l}\text { Identificar os } \\
\text { potenciais conflitos } \\
\text { de interesses } \\
\text { estabelecidos } \\
\text { entre indústrias } \\
\text { farmacêuticas e } \\
\text { pesquisadores } \\
\text { externos }\end{array}$ & $\begin{array}{l}\text { Pesquisas com } \\
\text { financiamento da } \\
\text { indústria farmacêutica } \\
\text { apresentam resultados } \\
\text { mais favoráveis e } \\
\text { conflitos de interesses } \\
\text { representam vieses, } \\
\text { podendo alterar } \\
\text { resultados. }\end{array}$ \\
\hline $\begin{array}{l}\text { Rev. Latinoam. Psicopat. } \\
\text { Fund., São Paulo, } 2013\end{array}$ & $\begin{array}{l}\text { A primeira tese } \\
\text { brasileira sobre a } \\
\text { alienação } \\
\text { mental: leituras, } \\
\text { plágios e ciência. }\end{array}$ & $\begin{array}{l}\text { Oda AMGR. } \\
\text { (11) }\end{array}$ & Scielo & $\begin{array}{l}\text { Apresentar o texto } \\
\text { "Considerações } \\
\text { gerais sobre a } \\
\text { alienação } \\
\text { mental" }\end{array}$ & $\begin{array}{l}\text { Trata-se de plágio, na } \\
\text { maior parte da tese. }\end{array}$ \\
\hline J. Health Inform. 2014 & $\begin{array}{l}\text { Programas de busca } \\
\text { de similaridade no } \\
\text { combate ao plágio: } \\
\text { contribuições para } \\
\text { educação }\end{array}$ & $\begin{array}{l}\text { Silva KL et } \\
\text { al.(12) }\end{array}$ & LILACS & $\begin{array}{l}\text { Identificar } \\
\text { programas anti- } \\
\text { plágios utilizados } \\
\text { como ferramentas } \\
\text { para auxiliar o } \\
\text { combate a fraudes }\end{array}$ & $\begin{array}{l}\text { Identificou-se } 97 \\
\text { publicações, sendo } \\
\text { analisadas } 58 \text {, dentre } \\
\text { as quais } 83 \% \text { referem- } \\
\text { se a detectores de } \\
\text { plágio de manuscritos } \\
\text { acadêmicos, } 12 \% \text { a } \\
\text { detectores de códigos } \\
\text { de programas e } 5 \% \text { a } \\
\text { detectores de plágio em } \\
\text { sítios eletrônicos. }\end{array}$ \\
\hline
\end{tabular}

Quadro sinóptico 1. Relação dos artigos identificados na pesquisa e suas principais características. Jequié/BA, 2015 
Publicar, publicar, publicar... até aonde vai a ética científica? - Patrícia Honório Silva Santos et al.

\section{Referências}

1. Miziara ID, Mello Júnior JF. Ética na pesquisa científica e na publicação de artigos em revistas biomédicas. (Editorial) Rev Bras Otorrinolaringol 2008; 74(3).

2. Miziara ID. Ethics in scientific publications: the double copyright problem. (Editorial) Braz J Otorhinolaryngol 2010; 76(5): 543.

3. Riis P. O Comitê Dinamarquês Sobre Desonestidade Científica. Bioética 1998; 6(2): 157-159.

4. Russo M. Ética e integridade na ciência: da responsabilidade do cientista à responsabilidade coletiva. Estudos Avançados 2014; 28(80).

5. Mendes KSS, Silveira RCCP, Galvão CM. Revisão integrativa: método de pesquisa para a incorporação de evidências na saúde e na enfermagem. Texto Contexto Enferm 2008; 17(4): 758-764.

6. Grieger MCA. Escritores-fantasma e comércio de trabalhos científicos na internet: a ciência em risco. Rev Assoc Med Bras 2007; 53(3): 247-251.

7. Garcia CC, Martrucelli CRN, Rossilho MMF, Denardin OVP. Autoria em artigos científicos: os novos desafios. Rev Bras Cir Cardiovasc 2010; 25(4): 559-567.

8. Santana CC. O tema da integridade científica nas pós-graduaçóes em saúde no Brasil. Rev Bioét 2010; 18(3): 637-644.

9. Guedes MC. Equívocos na publicação científica: algumas considerações, Psicologia USP 2011; 22(2): 387-398.

10. Souza RP, Rapoport A, Dedivitis RA, Cernea CR, Brandão LG. Conflitos de interesses na pesquisa médico-farmacológica. Rev Bioét (Impr.) 2013; 21(2): 237-240.

11. Oda AMGR. A primeira tese brasileira sobre a alienação mental: leituras, plágios e ciência. Rev Latinoam Psicopat Fund 2013; 16(4): 630-641.

12. Silva KL, Mello BLD, Pieri FM, Évora YDM, Melo MRAC. Programas de busca de similaridade no combate ao plágio: contribuiçóes para educação. J. Health Inform 2014; 6(1): 10-14.

13. Hossne WS, Vieira S. Fraude em ciência: onde estamos? Rev Bioét 2007; 15(1): 39-47.

14. Souza IMA, Caitité AML. A incrível história da fraude dos embriōes clonados e o que ela nos diz sobre ciência, tecnologia e mídia. Hist Cienc Saude-Manguinhos 2010; 17(2):471-493.

15. Gemperli R. A fraude em pesquisas científicas. (Editorial). Rev Bras Cir Plást 2013; 28(2).

16. Santos LHL. Sobre a integridade ética da pesquisa. São Paulo: FAPESP, 2011. Disponível em: http://www.fapesp.br/6566. Acesso em 07 de maio de 2015.

17. Office of Science and Technology Policy, na publicação do Federal Register: December 7, 2011 (v.65, n.235)), Disponível em: http://www.corporateservices.noaa.gov/ames/administrative_orders/chapter_202/202-735-D.pdf. Acessado em 11 de maio de 2015.

18. Committee on Publication Ethics (COPE). Diretrizes para prática da boa publicação: relatório 2003 docomitê de ética da publicação (COPE). Pró-Fono R. Atual. Cient. 2005; 17(2): 263-270.

19. Academia Brasileira de Ciências. Rigor e integridade na condução da pesquisa científica: guia de recomendaçôes de práticas responsáveis. Rio de Janeiro; 2013. Disponível em: http://www.abc.org.br/IMG/pdf/doc-4311.pdf. Acesso em: 12 de maio de 2015.

20. Shinkai RSA. Originalidade e Plágio: uma Questão de Autoria na Academia. (Editorial) Rev Esc Enferm USP 2014; 48(3).

21. Araújo VBC. Citação ou plágio? (Editorial). Rev Pan-Amar Saude 2011; 2(1): 9.

22. Azevêdo ES. Desafios da Bioética no Século XXI. Gaz. Méd. Bahia 2008; 78(1): 37-40.

23. Schmitz PD, Menezes M, Lins L. Percepção de Integridade Científica para o Estudante de Medicina. Rev. Bras. Educ. Med. 2012; 36(4): 447-455.

24. Conselho Nacional de Desenvolvimento Científico e Tecnológico. Ética e Integridade na prática Cientifica. Brasília: CNPq; 2011. Disponível em: http://www.memoria.cnpq.br/normas/lei_po_085_11.htm. Acesso em 12 de maio de 2015.

25. FAPESP. Código de Boas Práticas Científicas, 2011. Disponível em: http://www.fapesp.br/boaspraticas/codigo_050911. pdf. Acesso em 12 de maio de 2015.

Recebido: 21 outubro 2015

Aceito: 18 janeiro 2016 